\title{
Nutrition and dental decay
}

\author{
By M. N. NAYLoR, Department of Periodontology and Preventive Dentistry, Floor \\ 21 Guy's Hospital, London $S E_{1}{ }_{9} R T$
}

Contrary to a popularly-held view, dental decay is not a dietary disease, but one which is basically of microbial origin. Dietary carbohydrates, mainly mono- and disaccharides, are absorbed into dental plaque and broken down to organic acids by the micro-organisms present in dense concentrations. The acids produced cause the equilibrium between remineralization and demineralization to shift in favour of demineralization thus initiating the carious lesion.

Research in the field of dental caries using the human subject has been restricted for a number of reasons. First, dental decay is a disease of slow progression. Indeed, it has been estimated that a new lesion in a permanent tooth takes between I 8 and 60 months to become clinically detectable (Parfitt, 1956). Second, once established a lesion is irreversible, thus experimental induction of caries is wholly unethical. Third, because of the length of the study period it is quite impossible to obtain dietary histories and still less is it possible to control dietary intake. Fourth, perhaps the most important, diet is but one of a large group of secondary factors which contribute to an individual's experience of this multifactorial disease, many factors of which may be still unknown.

For these reasons most of the research which relates dental caries and diet has been carried out in animals, the rat model being by far the most common. Because of the dental and other obvious differences between man and rat, the transposition of these animal findings to the human species must be carried out with great caution. Clearly it is this problem which has greatly restricted the rate of progress in our knowledge and understanding of the precise role of dietary factors in relation to dental decay.

A survey of the literature would suggest that diet may influence decay experience in two ways. It may inhibit or it may promote disease. Far more is known about the latter than the former and, without question, the spearhead of prevention of caries has been directed towards restriction of caries-promoting foods rather than encouraging those which may actively inhibit.

Further, diet may affect the teeth systemically while the tooth is unerupted and in its developmental or maturation phase. Alternatively, and more importantly, it may exert its effect locally after the tooth has erupted.

\section{Dietary elements inhibiting decay}

Trace elements: fluoride. For almost half a century it has been appreciated that an optimum level of fluoride ions present in the diet (most conveniently in drinking-water) during the period of tooth development causes $50 \%$ or better 
reduction in caries experience (Murray, 1983 ). In practice this means that dietary fluorides should be included from birth to about 14 years of age. The precise mode of action of fluoride is not fully understood, although current thinking is that the presence of fluoride within the apatite lattice structure of dental enamel tends to create a local environment more favourable to remineralization even if it does not reduce acid solubility.

If fluoride is not present in the drinking-water at the optimum concentration ( $\mathrm{I} \mu \mathrm{g}$ fluoride ion/l in temperate climates), either naturally present or artificially added, it can alternatively be provided in tablet form or in the form of drops. Unlike fluoride in the water, tablets and drops require parental commitment for a period of $\mathrm{I}_{4}$ years for each child and, of course, do present a possible safety hazard. Quite small excesses of fluoride at crucial periods of tooth development can lead to mild, but by no means disfiguring, mottling of tooth enamel.

Fluorides also exert a topical effect; indeed, fluoride dentifrices act in this way. However, when swallowed, especially by infants and young children, such dentifrices can supplement the dietary fluoride and, if excessive, cause mild fluorosis. It is for this reason that many dentists are voicing increasing concern that in order to produce enhanced benefits from fluoride dentifrices, manufacturers are increasing the fluoride levels towards the legal limits set by regulatory bodies which would seem to be too high. Manufacturers would be far better advised to concentrate their research efforts on enhancing the efficacy of the fluoride at present levels or perhaps at even lower levels, rather than risk the adverse effects of increasing the dietary fluoride load.

Other elements present in the diet in trace amounts thought to influence caries experience include molybdenum, strontium, boron and lithium. The evidence for their effect is equivocal and if they do reduce caries the extent of the reduction is small compared with fluoride.

Minerals: non-trace amounts. Not surprisingly dietary calcium and phosphorus (the basic elements of the hard dental tissues) have attracted considerable interest. Much of the work has involved use of the rodent model but of especial interest are the studies reported by Sobel \& Hanok (1948, 1958) and Sobel (1958) who suggested that an optimum dietary $\mathrm{Ca}: \mathrm{P}$ value existed. This was investigated in man by Stanton (1969) who showed the optimum $\mathrm{Ca}: \mathrm{P}$ value to be 0.57 . This remarkable finding was tested by studying two groups of subjects, a caries-susceptible group and a caries-free group. In the caries-susceptible group the Ca:P value was either low (mean 0.39 ), or high (mean 0.79 ). In the caries-free group the mean $\mathrm{Ca}: \mathrm{P}$ value was 0.57 . Interesting as these findings are, they await replication. Dietary $\mathrm{Ca}$ and $\mathrm{P}$ may also act locally as was shown by Ostrom \& van Reen ( 1963$)$ by means of stomach-tube studies.

Based on the premise that dietary $\mathrm{Ca}$ and $\mathrm{P}$ in the form of phosphates are incorporated locally into the microbial plaque thus creating an environment which favours remineralization rather than demineralization of the hard tissue surfaces, a number of phosphate compounds have been studied. Amongst these are dicalcium phosphate and calcium glycerophosphate. 
In a 3-year human study, Ashley et al. (1974) provided children, aged I I-12 years at the beginning of the study, with sweets with and without addition of $3 \circ \mathrm{g}$ dicalcium phosphate dihydrate $/ \mathrm{kg}$. The findings indicated a small but significant reduction in caries between the test group and control group. However, interpretation of these findings was complicated by inclusion of two control groups, one of which was identical to a commercially-available sweet and the other contained $30 \mathrm{~g}$ flour $/ \mathrm{kg}$ as an additive to simulate the rough texture which the dicalcium phosphate gave to the test sweets.

This approach was vindicated in a further human study by Ashley et al. (1974) who showed that there was an inverse relationship between plaque $\mathrm{Ca}$ and $\mathrm{P}$ levels and the amount of new decay over the 2-year period of this longitudinal investigation.

Plaque $\mathrm{Ca}$ and $\mathrm{P}$ levels have also been studied in response to dietary calcium glycerophosphate. Bowen (1972) showed that the plaque Ca but not the P level was raised when a diet containing ro $\mathrm{g}$ calcium glycerophosphate/ $\mathrm{kg}$ was given to monkeys. Brook et al. (1975) in a human study gave children cereal tablets with and without ro $\mathrm{g}$ calcium glycerophosphate $/ \mathrm{kg}$ four times daily for 3 months. Both $\mathrm{Ca}$ and phosphate levels were raised but only the phosphate levels achieved a statistically-significant increase. Indeed, it was for these reasons that calcium glycerophosphate was selected for inclusion in a dentifrice for the purpose of enhancing the decay-reducing effect of fluoride. In a recently concluded clinical trial it has been shown that the addition of calcium glycerophosphate significantly improved the efficacy of an already established fluoride dentifrice (Mainwaring \& Naylor, 1979).

Vitamins. Many generations of expectant mothers and mothers of infants have been advised by their dentist to ensure an adequate, even enriched, intake of vitamins to ensure that their child has 'strong and healthy teeth'. Sadly it was in these generations that the caries prevalence in children continued to increase. This advice was based on the established relationship between mineralization of hard tissues and vitamins A, D and C. Indeed, the work of Mellanby (1923, 1937) and others supported this view in that deficiencies of vitamin $D$ in dogs caused hypocalcification and that a hypocalcified tooth was more susceptible to decay. Certainly extreme deficiencies can cause hypocalcification in puppies but the work of Marshall-Day (1944) in rachitic areas of India failed to show any relationship between clinical rickets and dental hypoplasia. Furthermore, the caries levels were very low indeed, although the children with no evidence of rickets had a higher level of decay than those with moderate to severe rickets.

Energy foods. As long ago as 1954 , Constant et al. (1954) demonstrated in the cotton-rat model that oat hulls included in the diet exerted an anticaries effect. This activity was subsequently confirmed in a number of other rodents, but it has never been tested in the human subject and, in view of the complex problems associated with human long-term dietary studies, it is unlikely that it ever will be.

The anticaries effect of oat hulls was confirmed by Madsen (1958), Taketa \& Phillips (1957), Buttner \& Muhler (1959), McClure (1964) and Stookey \& 
McDonald (1974) using rodent models given cariogenic diets comprising moderate and high percentages of mono- and disaccharides. Other seed hulls including those of barley, cocoa, cottonseed, peanut, pecan, soya bean and sunflower have also been shown to confer an anticaries effect on cariogenic diets in the cotton-rat model (Madsen \& Edmonds, I962). It is suggested that the anticaries effect is induced by the polyphenols present in the hulls exerting an antibacterial or an anti-demineralization role.

That cocoa products exerted an anti-caries effect was first indicated by Stralfors ( 1966 ) who carried out a series of experiments using the hamster caries model. Employing a cariogenic diet which contained $50 \mathrm{~g}$ sucrose $/ \mathrm{kg}$, the addition of $20 \mathrm{~g}$ whole cocoa powder $/ \mathrm{kg}$ reduced the amount of caries by $42 \%$. Increasing the cocoa level to $200 \mathrm{~g} / \mathrm{kg}$ reduced the caries by $85 \%$. These findings served to regenerate interest in the results of a human study carried out at the Vipeholm Hospital in Lund and reported by Gustafsson et al. (1954) in which subjects provided with a diet containing sucrose and chocolate experienced a much-reduced caries increment when compared with those receiving the same amount of sucrose in other forms.

Attempts to determine the precise mechanism of the anti-caries activity of cocoa have been confusing. Stralfors (1966) claimed it lay in the lipid-free portion but Wynn et al. (1960) found no caries inhibition until lipid was added to the diet. More recent work reported by Paolino (1982) has demonstrated both an anticaries and an antiplaque activity for cocoa and has indicated that a biochemical mechanism may be implicated in which glucosyl tranferase activity is inhibited. This enzyme, frequently referred to as dextransucrase ( $E C$ 2.4.I.5) is responsible for the elaboration of plaque extracellular polysaccharide from sucrose.

\section{Dietary elements promoting decay}

Carbohydrate. Far more is known about dietary factors which promote dental decay than those which inhibit it, and of those the carbohydrates are the group most firmly implicated. As long ago as the declining years of the last century, Miller (1890) demonstrated that when teeth were incubated with saliva and carhohydrates, acids were formed which attacked and disintegrated tooth surfaces. When teeth were incubated without carbohydrate, acids did not form and the teeth were not attacked. Miller ( 1890 ) concluded from these simple and primitive experiments that salivary bacteria broke down carbohydrates to form acids which in turn caused a tooth to become carious. This conclusion became embodied into the chemico-parasitic theory of Miller ( 1890 ) which for almost one century has dominated thinking on the nature and cause of caries.

It must be remembered, however, that Miller's (1890) experiments carried out in vitro are a far cry from the in vivo situation in which the lesion develops not in saliva but beneath a dense, sticky gelatinous plaque comprising micro-organisms of many kinds embedded within a matrix of extracellular carbohydrate. Such plaques are relatively impermeable to saliva and its component buffering systems, and to the larger carbohydrate molecules. In practical terms, the carbohydrates which are 
readily absorbed into plaque are the mono- and disaccharides, the commonest of which, of course, is sucrose. There is abundant evidence to support this view based on laboratory and animal experiments, human in situ studies and epidemiological investigations in which confined populations were investigated. As has been pointed out previously the findings of laboratory and animal experiments must be transposed to the human situation with care. Nevertheless, there are a number of key experiments using animal models where the findings have been confirmed in human studies.

Innumerable rodent-model studies have demonstrated that by placing animals on a diet comprising high levels of sucrose causes carious lesions to appear within a period of a few weeks. It has also been shown that the earlier the high sucrose levels are established after weaning, the greater is the caries produced.

Of the human epidemiological studies carried out, the one involving the inhabitants of the island of Tristan da Cunha is perhaps the most dramatic. Before $194^{\circ}$ the 200 or so people of this South Atlantic island, mostly European in origin, consumed a diet very low in sugar. Occasional visits to the island by dental officers of the Royal Navy reported a near zero prevalence of tooth decay. In $194^{\circ}$ the island assumed a strategic wartime importance and as a consequence foods containing sugar were introduced to the island. From then on there was a steady increase in decay rates which were faster in children than adults. Thus in the space of less than one generation an increase in dental decay experience exactly paralleled an increase in sugar consumption in an isolated community whose only major change in life-style was a dietary upheaval (Fisher, 1968).

An important human study carried out at the Vipeholm Hospital near Lund in Sweden was reported by Gustafsson et al. (1954). This study indicated that it was not so much the amount of sugar consumed which was important but rather the pattern of consumption.

Diets containing sucrose consumed at meal times only, either in liquid or dry form, produced approximately similar low increments in decay as did sucrose-free diets. However, those subjects who ate the same amount of sugar in the form of toffees available at all times of the day experienced dramatic increments in near decay. This finding has been investigated further by Konig (1969) who, in a series of closely-controlled experiments, showed a direct relationship between the daily number of meals and caries experience in rats whose total daily intake of food was identical. In a human study based on clinical examinations of deciduous teeth and carefully-compiled dietary histories seeking to reveal between-meal eating habits, Weiss \& Trihart (1960) showed a direct relationship between decay experience and the number of between-meal snacks. It would seem clear, therefore, that caries experience is not a direct function of the amount of sugar consumed but rather the frequency of eating and the form in which it is ingested.

Attempts have been made to assess the relative cariogenicity of the various mono- and disaccharides in common use for food manufacturing. A study using the rat model was reported by Guggenheim et al. (1966) in which sucrose was shown to have far greater caries potential than its fellow mono- and disaccharides. For 
obvious reasons it has not been possible to conduct a human investigation of comparable nature but, in a series of plaque-growth studies in dental students, no difference was demonstrated between sucrose- and maltose-loaded diets (Skinner et al. 1982). This is clearly an area for further investigation notwithstanding the problems of long-term studies.

Finally, attempts to identify non-cariogenic, energy-containing sucrose substitutes must be mentioned. Calcium sucrose phosphate is an example of an organic phosphate additive which showed significant cariostatic effects in vitro and in vivo in animal and in pilot human studies but, for various reasons, this compound seems to have lost favour.

Xylitol, a pentose alcohol derived from wood and other cellulose products, has an energy value similar to sugar as well as comparative and attractive sweetness. In a series of meticulously-conducted studies, now known collectively as the 'Turku Sugar Study', Sheinin \& Makino (1975) demonstrated over a 2-year period the substantially-reduced cariogenicity of xylitol when compared with sucrose and fructose.

In this brief and superficial review the role of diet as perhaps the most important secondary factor in the onset of dental decay has been considered. The problems of transposing laboratory and animal studies to the human situation have been pointed out. The cumulative evidence implicates sucrose as the most important single dietary factor. However, the evidence is equally clear that it is not the absolute amount of sucrose consumed which is important but the pattern of eating.

In purely practical terms the difficulty which the dental health educator has is motivating people to eat the sucrose content of their diet correctly and to withstand the entreaties of manufacturers via the media to inculcate habits of eating sticky sucrose-containing foods between meals.

\section{REFERENCES}

Ashley, F. P., Naylor, M. N. \& Emslie, R. D. E. (1974). British Dental Fournal 136, 361-366.

Bowen, W. H. (1972). Caries Research 6, 43-51.

Brook, A. H., Winter, G. B. \& Gawthorpe, J. (1975). Caries Research 9, 156-162.

Buttner, W. \& Muhler, J. C. (1959). Journal of Dental Research 38, 823-824.

Constant, M. A., Sievert, H. W., Philips, P. H. \& Elvehjem, C. A. (1954). Fournal of Nutrition 53, I 7-27.

Fisher, F. J. (1968). British Dental fournal $125,447-453$.

Guggenheim, B., Konig, K. G., Herzog, E. \& Muhlemann, H. R. (1966). Helvetica Odontologica Acta I0, IOI-I I 3 .

Gustafsson, B. E., Quensel, C. E., Lanke, L. S., Lundquist, C., Grahnen, H., Bonow, B. E. \& Krasse, B. (1954). Acto Odontologica Scandinavica I1, 232-364.

Konig, K. G. (1 969). Archives of Oral Biology 14, 991-993.

McClure, F. J. (1964). Archives of Oral Biology 9, 21 9-22 I.

Madsen, K. O. (1958). A study of possible anticariogenic factors present in certain natural products. Doctorial Dissertation, University of Wisconsin.

Madsen, K. O. \& Edmonds, E. J. (I962). Fournal of Dental Research 41, 405.

Mainwaring, P. J. \& Naylor, M. N. (1979). Caries Research $13,105$.

Marshall-Day, C. D. (1944). British Dental Journal 76, $115^{-1} 43$.

Mellanby, M. (1923). British Dental Journal 44, 1-1 3 .

Mellanby, M. (1937). British Dental Yournal 62, 24 I-252. 
Miller, W. D. (1890). Micro-organisms of the Human Mouth. Philadelphia: S. S. White \& Co.

Murray, J. J. (1983). The Prevention of Dental Disease, Chapter 3, pp. $83^{-158}$. Oxford: Oxford Medical Publications.

Ostrom, C. A. \& van Reen, R. (1963). Fournal of Dental Research 42, 732-738.

Paolino, V. (1982). In Foods, Nutrition and Health, vol. 2, pp. 43-58. Proceedings of 3 rd Annual Conference of the American Dental Association and Health Foundation. Chicago: American Dental Association and Health Foundation.

Parfitt, G. J. (1956). British Dental fournal 100, 204-207.

Sheinin, A. \& Makino, K. K. (1975). Acta Odontologica Scandinavica 33, Suppl. 70, 1-349.

Skinner, A., Connolly, P. \& Naylor, M. N. (1982). Archives of Oral Biology 27,603-608.

Sobel, A. E. (1958). Fournal of Dental Research 37, 631-637.

Sobel, A. E. \& Hanok, A. (1948). Fournal of Biological Chemistry 176, 1103.

Sobel, A. E. \& Hanok, A. (1958). Fournal of Dental Research 37,63 I.

Stanton, G. (1969). New York State Dental Yournal 35, 399-407.

Stookey, G. K. \& McDonald, J. L. (1974). Fournal of Dental Research 53, 107-I 12.

Stralfors, A. (1966). Archives of Oral Biology I1, 61 7-626.

Taketa, F. \& Phillips, P. J. (1 957). Fournal of the American Dietetic Association 33, 575.

Weiss, R. L. \& Trihart, A. H. (1960). American fournal of Public Health 50, $1097^{-1} 104$.

Wynn, H., Haedi, J. \& Law, M. L. (1960). Fournal of Dental Research 39, 153-157. 